\section{Review Article}

Transfusion Medicine

Ann Lab Med 2022;42:306-313

https://doi.org/10.3343/alm.2022.42.3.306

ISSN 2234-3806 elSSN 2234-3814

\section{ANNALS OF LABORATORY MEDICINE}

\title{
Current State of Blood Management Services in Korea
}

\author{
Hyun Ok Kim (iD, M.D., Ph.D. \\ Department of Laboratory Medicine, Yonsei University College of Medicine, Seoul, Korea
}

Blood is lifesaving; however, it can neither be limitlessly acquired nor artificially produced. The supply and use of blood, as an invaluable biological commodity, necessitate systematic and rational management under governmental guidance to ensure safe and reliable transfusions. Despite Korea's blood donation rate of 5.04\%, which is higher than the 3.15\% in high-income countries as reported by the WHO, the demand for blood exceeds the availability. This is due to the birthrate decline, dearth of young donors, and growing and aging recipient population. This review outlines the Korean blood management system, with a focus on blood service data from 2020, with the aim to delineate the current state of Korea's blood management system and the policies established to address the imminent blood shortage. Each policy is described in detail to provide helpful information for blood management services in other countries.

Key Words: Blood management, Service data, Korea
Received: August 16, 2021

Revision received: September 10, 2021

Accepted: December 1, 2021

\section{Corresponding author:}

Hyun Ok Kim, M.D., Ph.D. Department of Laboratory Medicine, Yonsei University College of Medicine, 50-1

Yonsei-ro, Seodaemun-gu, Seoul 03722, Korea

Tel: +82-2-2228-2444

Fax: +82-2-313-0956

E-mail: hyunok1019@yuhs.ac

(c) 1 Korean Society for Laboratory Medicine
This is an Open Access article distributed under
the terms of the Creative Commons Attribution
Non-Commercial License (https://creativecom-
mons.org/licenses/by-nc/4.0) which permits
unrestricted non-commercial use, distribution,
and reproduction in any medium, provided the
original work is properly cited.

\section{INTRODUCTION}

Modern transfusion medicine originates from field medicine in World War II, when bloody casualties demanded transfusions to save lives. The Red Cross implemented blood services across multiple countries as a movement in humanitarian acts. Later, scientific research and clinical applications became additional purposes. Per the recommendation of the WHO, governments acquired an increasingly important role and a higher level of responsibility in the blood services, alongside the Red Cross [1].

The role of government is emphasized for the following reasons. First, voluntary non-remunerated blood donors give blood for free. As such, blood donation must be operated in the most ethical and transparent manner to receive the public's trust and support. Second, the economic concept of market competition does not apply to the blood business. Blood services are subject to price competition even if there are multiple institutions because the management cost increases along with medical advances, such as in preventing the spread of infectious diseases, protecting the health of blood donors and recipients, and providing highquality blood products. Third, there is a limit to benchmarking the case of developed countries because blood services are affected by a country's unique environment and system, ongoing epidemics, culture, and tradition. The decrease in the number of blood donors worldwide, as seen in data on changes in the age structure of the global population, is a portent of future blood shortages. In many countries, plans for national blood management services are being prepared by the state [2-4]. In this review, I present a plan for the blood management program in Korea by examining the past and present trends in the country's blood services.

Historical Background of Korea's Blood Management System The first report on blood transfusion in Korea provided a review 
of 161 transfusion practices carried out between 1931 and 1935 [5]. In 1950, during the Korean War, the US military introduced blood transfusions and the Korean Navy established the first blood bank. The blood management act was enacted in 1970, and the national blood service was consigned to the Korean Red Cross (KRC) in 1981. In 1998, 100\% voluntary, non-remunerated blood donor systems were achieved, and paid services were forbidden by law [6].

In 2004, the KRC confirmed transfusion-transmitted human immunodeficiency virus (HIV) infection in six subjects, resulting in a social scandal that led to the review of the donation history of subjects diagnosed as having HIV infection [6, 7]. These events highlighted the monopoly of the KRC over blood services and the government's lack of involvement in blood management. Thus, the government established The National Blood Safety Improvement Project (2004-2009) that focused on the prevention of transfusion-transmitted infections (TTI). The project included the following initiatives: (1) changing the blood donation type from group donations to individual donations, (2) increasing governmental investments related to blood management to USD 320 million over five years, (3) improving national monitoring systems for transfusion, (4) consolidating laboratory centers and automating screening tests to reduce errors in efficient operation, (5) introducing highly sensitive screening tests to prevent TTI, and (6) keeping aliquots of all donated blood samples for 10 years to enable review in the event of adverse transfusion reactions, including transfusion-related infections [8]. This project ensured infection prevention in the Korean blood services.

\section{Structure of the Blood Management System}

The blood management system is supervised by the Ministry of Health and Welfare (MOHW) and the Ministry of Food and Drug Safety (MFDS). The MOHW formulates policies for the safe management of blood services and stable supply of blood. The MFDS oversees work related to plasma derivatives. The division of Blood Safety Surveillance, which is in charge of the National Institute of Organ, Tissue, and Blood Management, is affiliated with the MOHW.

The KRC has 15 regional blood centers nationwide, three laboratory centers for the screening of infectious markers in donated blood, a blood transfusion research institute, and a plasma fractionation center. Non-KRC blood centers include Hanmaeum Blood Center that can supply blood for hospitals, and 53 hospital blood centers that can supply blood only for use in the affiliated hospitals (Fig. 1).

\section{Blood Donation}

Data on blood donation and supply in Korea for 2010-2020 have been reported by Roh, et al. [9]. The KRC received $94 \%$ of the total blood donation volume, whereas non-KRC blood centers received $6 \%$. Hospital blood centers undergo regular certification reviews by the MOHW for receiving blood donations. In recent years, except for donations for autotransfusion and leukapheresis, the level of blood donations in hospital blood center is low, and the supply collected is considerably insignificant. In 2020, the national blood donation rate in the entire population was $5.04 \%$, which is slightly higher than the rate of

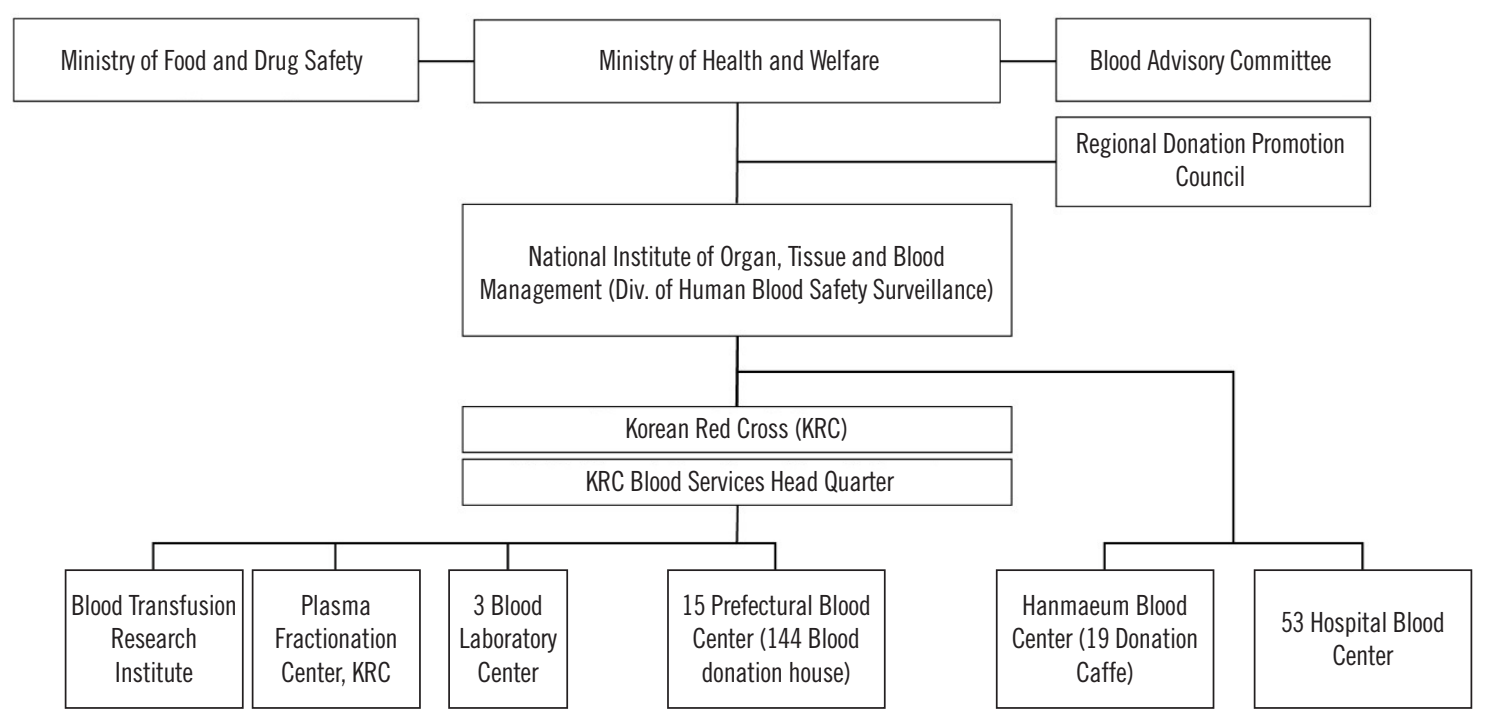

Fig. 1. Structure of the blood management system in Korea. 


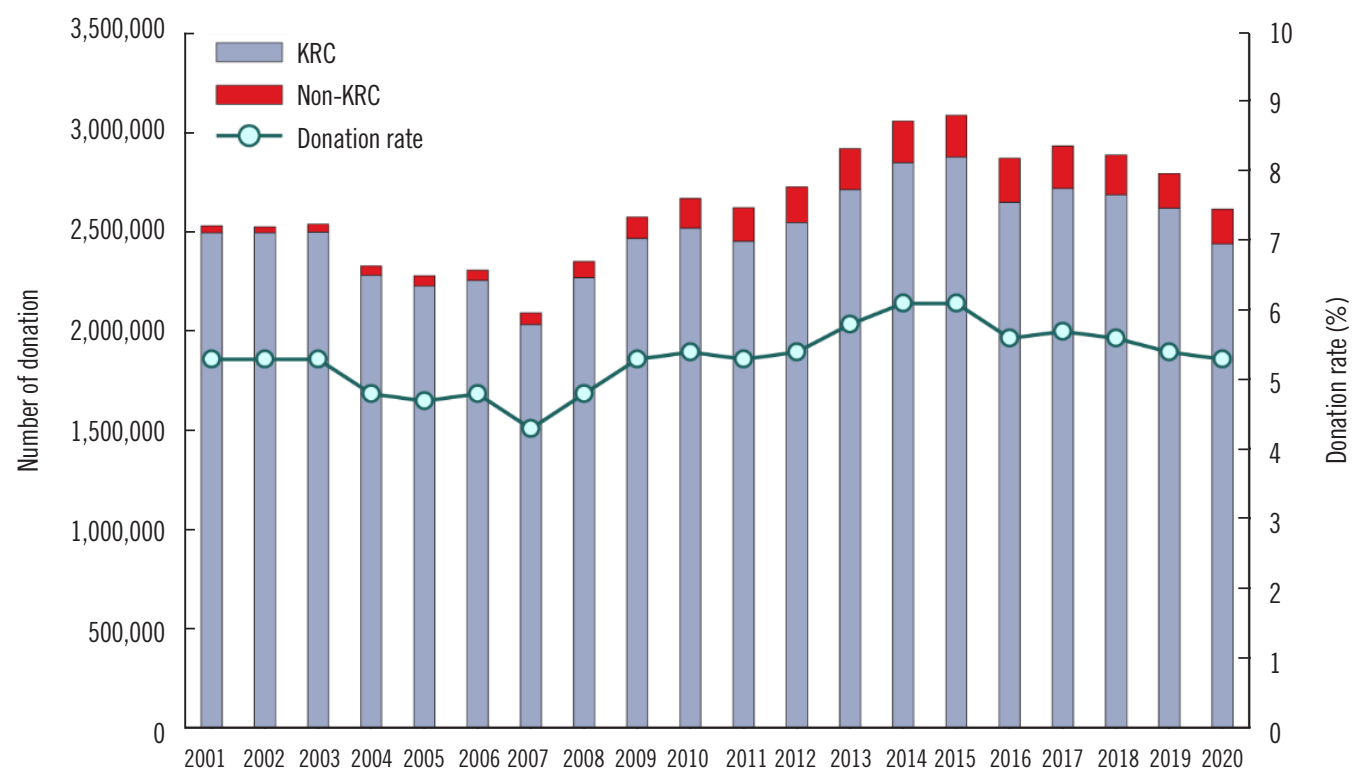

Fig. 2. Blood donation rate. The decrease in the number of blood donors during 2004-2007 is due to transfusion-transmitted human immunodeficiency virus infections, that in 2016 due to MERS-CoV infections, and that in 2020 due to COVID-19.

Abbreviations: KRC, Korean Red Cross; MERS-CoV, Middle East respiratory syndrome coronavirus; COVID-19, coronavirus disease.

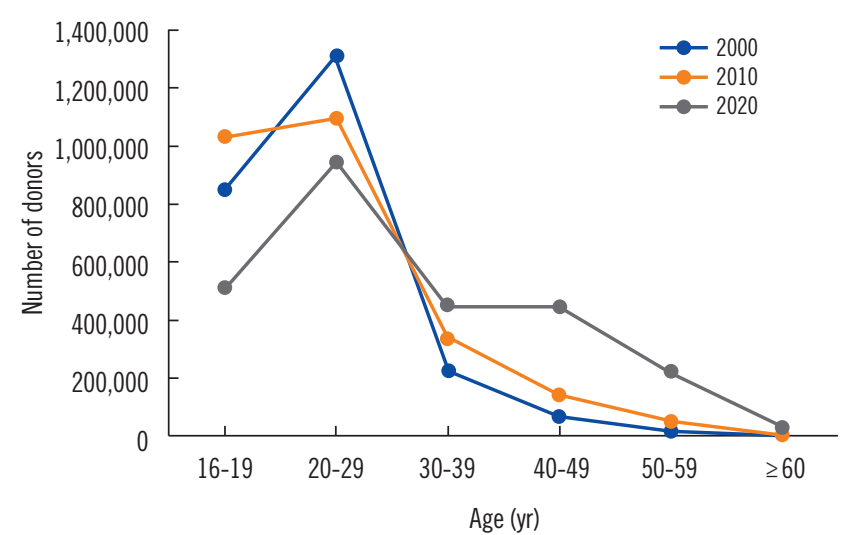

Fig. 3. Numbers of blood donors by age group in 2000,2010 , and 2020.

\subsection{5\% in high-income countries (Fig. 2) [1].}

The 2,611,401 blood donations collected in 2020 included 1,964,633 whole blood donations, 245,663 platelet apheresis donations, and 400,653 plasma apheresis donations. Registered donors accounted for $49.9 \%$ of the total blood donation volume [10]. The numbers of blood donations by age group are shown in Fig. 3. People in their teens and twenties are the major donor group and provide approximately $65 \%$ of the blood donations in the country. Approximately one third (28\%) is provided by donors in their 30s and 40s, and 7\% by those in their 50s and 60s. Given the low donation rates in the latter age groups, the government is supporting policies to promote blood donations in middle-aged people.

Whole blood is collected in two volumes, $320 \mathrm{~mL}$ and $400 \mathrm{~mL}$, excluding anticoagulants and is processed into components, which are supplied for transfusion to 2,487 hospitals. Information on donation for various medical conditions, lists of medications, vaccinations, and risky behaviors prohibiting blood donation, and donor questionnaire cards can be accessed anywhere in the country via the Electronic Health History Assessment System on the KRC website (https://bloodinfo.net). In mobile donation buses, a donor's blood donation history and previous donation test results can be checked on site using mobile devices. Potential donors who were not eligible for blood donation in the past are filtered through this system and are deemed ineligible to donate blood.

\section{Donor Screening Tests}

The KRC has three laboratory centers for donor screening (Fig. 4). ABO blood group, Rh subgroup, and unexpected antibody screening tests are conducted for all donated blood. The hepatitis $B$ virus (HBV) surface antigen test method has changed throughout the decades: immunoelectrophoresis (IEP) test was used since 1975, enzyme-linked immunosorbent assay (ELISA) since 1990, and chemiluminescent immunoassay (ChLIA) using the Abbott PRISM instrument (Abbott, Wiesbaden, Germany) since 2007. HBV nucleic acid testing (NAT) has been used since 2012, anti-HIV test has been conducted since 1987, and ELISA- 


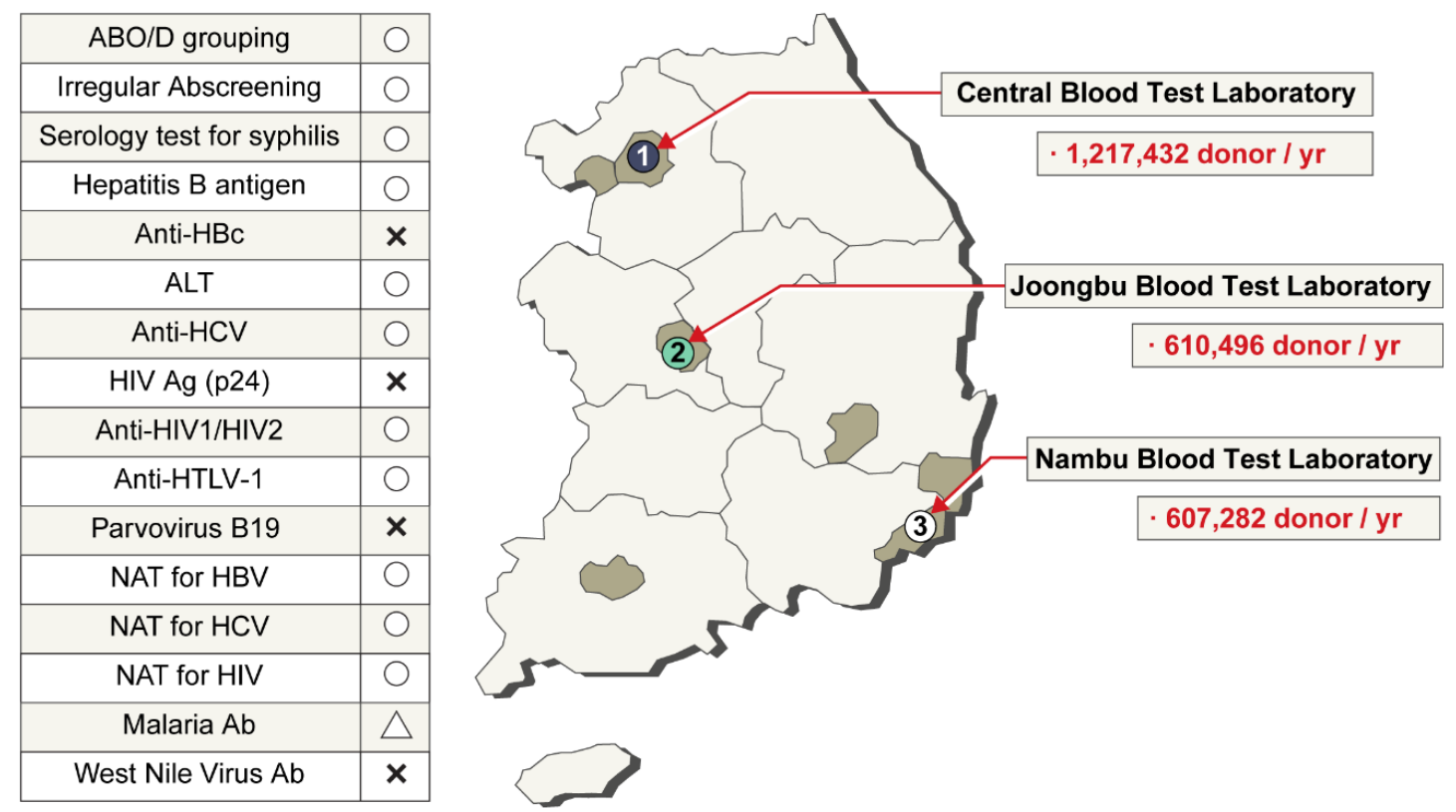

Fig. 4. Three laboratory centers for donor screening. In the list of tests conducted in Korea on the left, $\bigcirc$ refers to a test conducted on Korean blood donors, and $\triangle$ refers to a test conducted on resident donors in the northwest region bordering North Korea.

Abbreviations: NAT, nucleic acid amplification testing; HIV, human immunodeficiency virus; HCV, hepatitis C virus; HBV, hepatitis B virus; HTLV, human Tcell lymphotropic viruses.

based anti-hepatitis $\mathrm{C}$ virus (HCV) test has been conducted since 1991. HIV NAT and HCV NAT began in 2005. Initially, NAT was conducted using pooled samples, but at present, individual samples are tested using the Procleix Ultrio Plus Assay (Grifols Diagnostics Solutions, Emeryville, CA, USA). ChLIAbased human T-lymphotropic virus test has been conducted since 2009. The presence of syphilis is serologically tested using the Treponema pallidum particle agglutination test. ALT is also tested, and the threshold for disposal is $101 \mathrm{IU} / \mathrm{L}$. ELISAbased anti-malaria test is conducted only for donors living in the northwest region bordering North Korea (Fig. 4). All TTI screening test results are recorded in a computerized system. By entering the donor's resident registration number, the blood donation history and test results can be viewed in real time at the blood donation site. Since 2004, aliquots of donated blood are stored for 10 years for review purposes. In 2009, a donor with a four-year donation history was confirmed to have AIDS. The stored blood sample tested positive in HIV NAT. All patients who received packed red blood cells (RBCs), platelets, and fresh frozen plasma were cancer patients and died during short-term treatment. No suspected clinical signs of HIV infection were attributed to the blood transfusions. Except for this case, up to 2020, there have been no reports of HIV, HCV, or HBV infection through blood transfusions [7, 11].
Table 1. Estimated numbers of blood components supplied by blood centers in 2020 [10]

\begin{tabular}{lr}
\hline Item & \multicolumn{1}{c}{ N } \\
\hline Blood components distributed by blood centers & $4,447,974$ \\
Hospitals that received blood components & 2,487 \\
Distributed blood components (units) & \\
Whole blood & 483 \\
RBCs & $1,524,234$ \\
Washed RBCs & 1,746 \\
Prefiltered leukoreduced RBCs & 388,775 \\
Whole blood-derived platelets & $1,615,163$ \\
Apheresis platelets & 239,237 \\
Fresh frozen plasma & 587,916 \\
Cryoprecipitates & 90,008 \\
Others* & 412 \\
Total & $4,447,974$ \\
\hline
\end{tabular}

*Whole blood-derived white blood cells and platelet-rich plasma were supplied according to the needs of the hospitals.

Abbreviation: RBCs, red blood cells.

\section{Blood Use In Hospitals}

The blood components supplied to hospitals by blood centers in 2020 are summarized in Table 1. In the past three years, Korea has frequently experienced blood shortages. The situation was 
exacerbated by the decrease in blood donations due to the $\mathrm{CO}$ VID-19 pandemic in 2020. The government and hospitals are increasingly interested in patient blood management. Blood transfusion guidelines for each situation have been established, and active patient blood management education for medical staff has been launched.

The KRC and Hanmaeum Blood Center electronically report the amount of blood supply and retention in real time to the portal site of the MOHW. The average blood stock is maintained for five days, but recently, it often decreased to less than three days. Korea's RBC supply for one day is 4,945 units. If the average blood stocks decrease to less than three days, a caution warning is issued according to the Blood Supply and Demand Crisis Response Manual. The warning lasted five days in 2019, which worsened to 13 days in 2020 (Fig. 5) [12].

In 2020, 1,915,238 units of blood components were supplied to 2,487 hospitals from the KRC Blood Center and Hanmaeum Blood Center. Hospitals using less than 500 RBC units per annuum accounted for $85 \%$ of all hospitals that used blood (Fig. 6). The patient pays 5\%-20\% of the blood transfusion fee depending on the disease, and the remaining $80 \%-95 \%$ is covered by the national medical insurance.

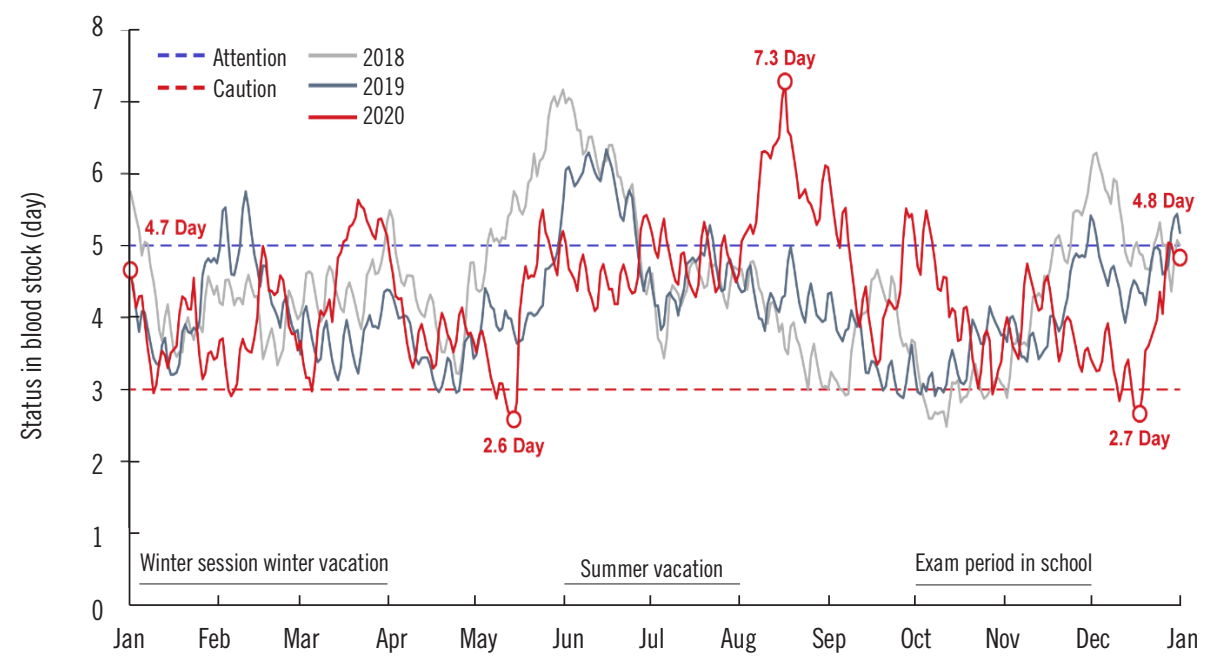

Fig. 5. Daily monitoring of the stored amount of RBCs that the KRC Blood Center can supply to hospitals. Abbreviations: RBCs, red blood cells; KRC, Korean Red Cross.

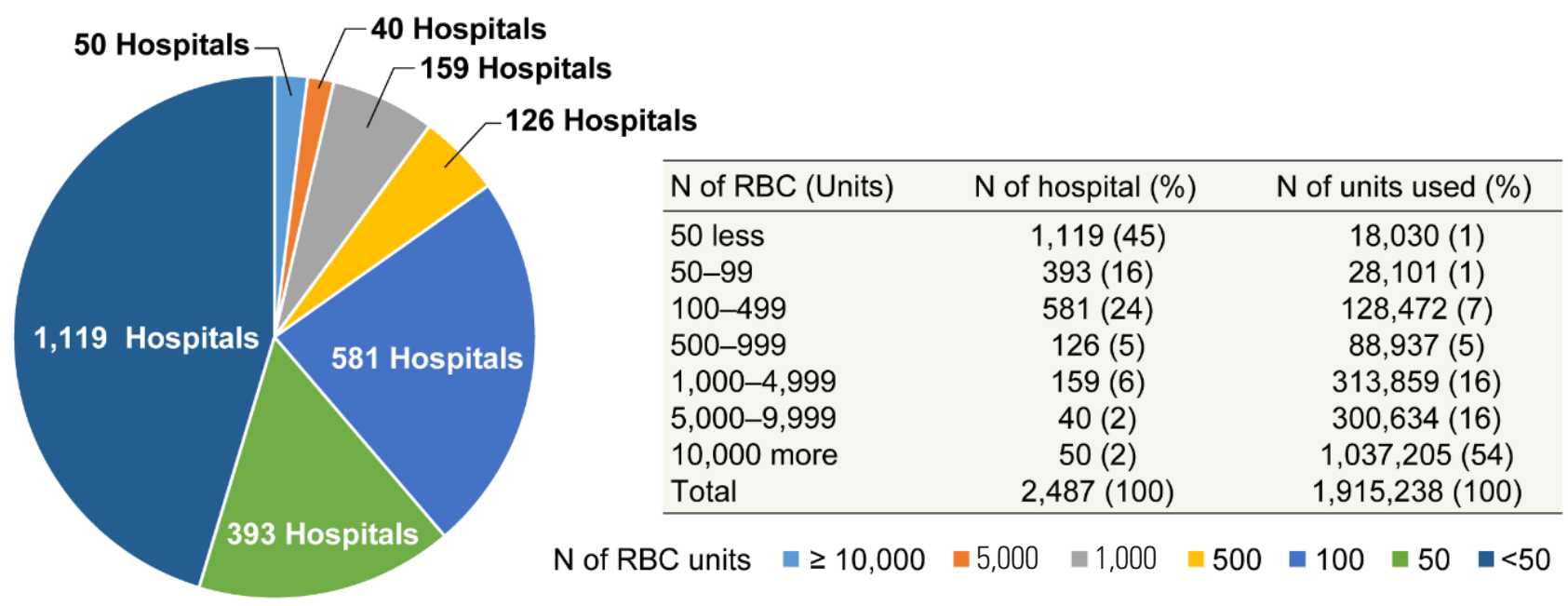

Fig. 6. Numbers of hospitals according to RBC use. Abbreviation: RBC, red blood cell. 


\section{Hemovigilance System}

In 2008, a national hemovigilance report system was established. The system is supported financially by the MOHW but is independently operated by the Korean Society of Blood Transfusion. The system identifies adverse transfusion reactions across the country. The operation of a constant monitoring system is expected to lead to strategies to strengthen the safety of blood transfusions and prevent transfusion accidents. The investigation of adverse cases started with voluntary input by the hospital blood banks, but in 2014, a regulation was established that mandated transfusions and all adverse blood-related reactions, including near misses, to be reported to receive a blood management fee from the national medical insurance. This initiative resulted in a rapid increase in hospital-provided data. In 2020, a total of 267 hospitals participated and reported 2,787 adverse events (Fig. 7).

Each hospital is required to enter cases on the hemovigilance website (http://www.kohevis.or.kr) by month or by occurrence period. In case of no adverse occurrences, a zero report is required. Of the 2,787 reports, 2,569 cases involved transfusionrelated symptoms, including 218 cases related to transfusion errors and 74 cases related to blood collection errors, 44 of which were related to blood collection from other patients (Fig. 8) [13, 14].

\section{Blood Information Database}

The KRC operates the Blood Information Management System (BIMS) and Blood Information Sharing System (BISS) for the data management of blood donation and blood supply in the blood services. The BISS program stores records of all blood donors since 1981. The objectives of the BISS are to enable real-time verification of donor eligibility, information sharing on urgent and rare blood groups, and hospital ordering of blood components. BISS data are backed up at the National Disaster Recovery Center.

\section{National Recipient-Triggered Traceback System}

Anyone who suspects transmission of hepatitis or other infections

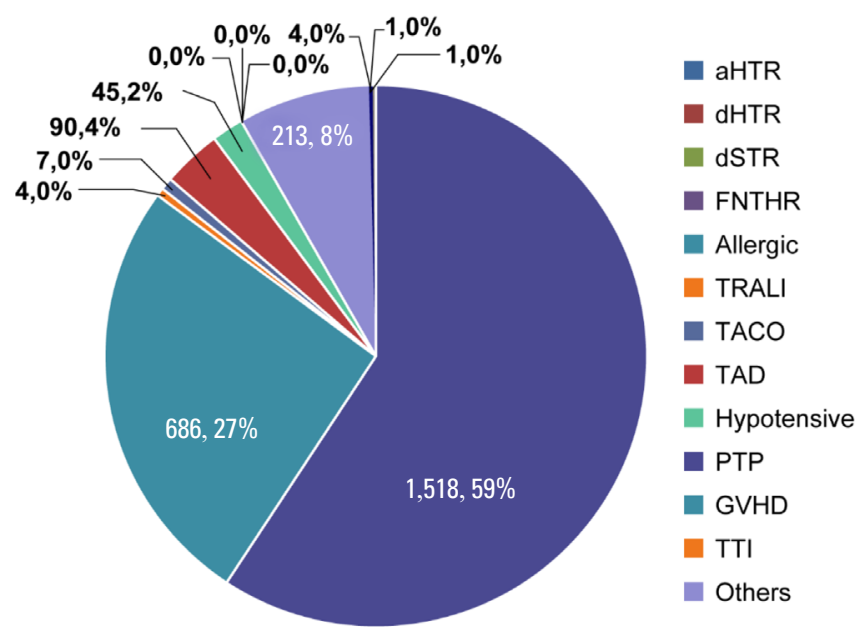

Fig. 8. Percentages of adverse transfusion reactions according to the symptom type.

Abbreviations: aHTR, acute hemolytic transfusion reaction; dHTR, delayed hemolytic transfusion reaction; dSTR, delayed serological transfusion reaction; FNHTR, febrile non-hemolytic transfusion reaction; allergic, allergic reaction; TRALI, transfusion-related acute lung injury; TACO, transfusion-associated circulatory overload; TAD, transfusion-associated dyspnea; Hypotensive, hypotensive reaction; PTP, post-transfusion purpura; GHVD, graftversus-host disease; TTI, transfusion-transmitted infection.

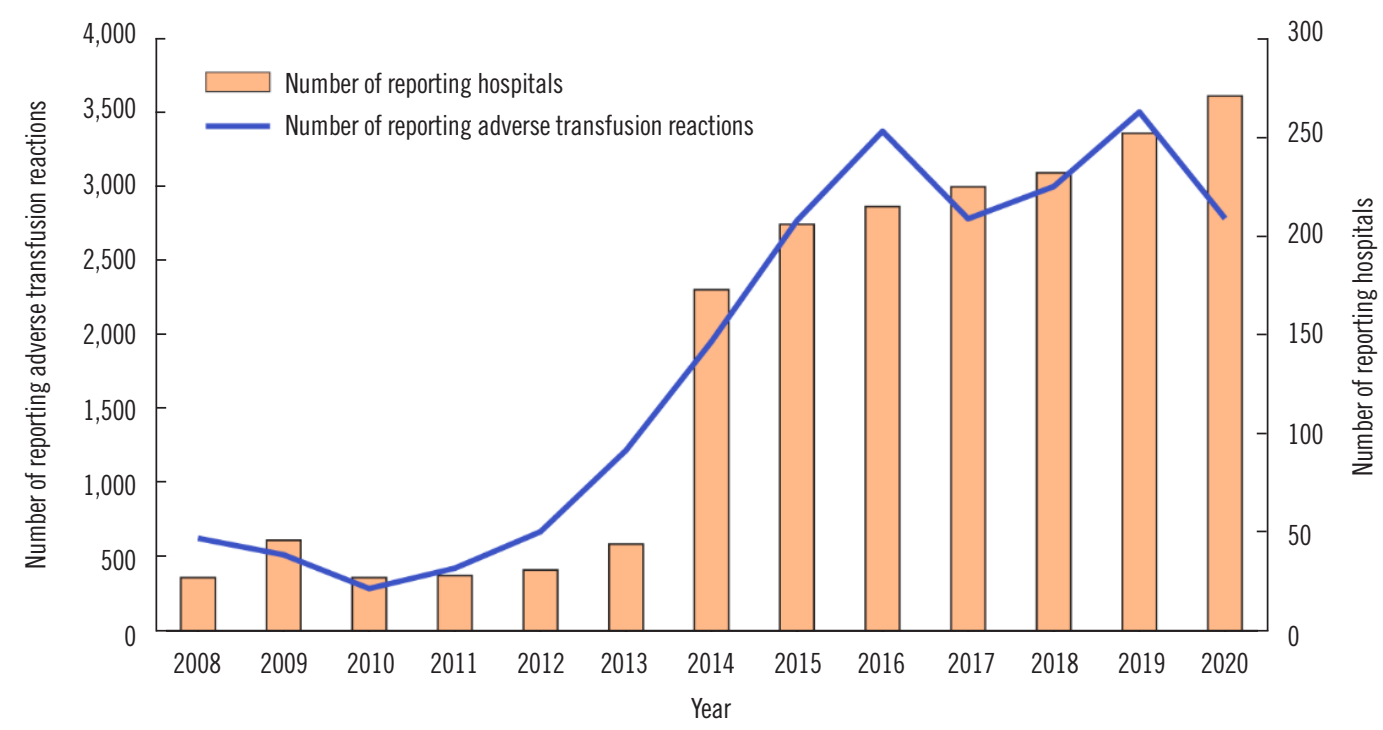

Fig. 7. Numbers of reporting hospitals and reported adverse transfusion reactions. 
after receiving blood transfusion can go to the hospital where the blood transfusion was received and request a traceback. To start an investigation, the hospital submits the appropriate document with the patient's current laboratory test results to the regional public health center. Data collected in the traceback system are retrospectively reviewed and reassessed in six phases. When data that allow ruling out adverse reactions related to transfusion are available at a certain stage, the traceback process is stopped. The result is informed to the patient via the hospital that requested the traceback (Fig. 9).

HIV transfusion accidents in 2004 highlighted the need for the development of a safety system for the Korean blood services. A national recipient-triggered trace system was established, which confirmed earlier TTI cases. The goal of stable supply of safe blood to the people has been achieved. Since 2008, no HBV, $\mathrm{HCV}$, or HIV infections through blood transfusions have occurred (Table 2).

\section{CONCLUSIONS AND FUTURE PERSPECTIVES}

Each country's blood service system needs to comprehensively consider expert opinions, the consensus of the people, and the appropriateness of the financial burden.

In future, blood services in Korea should aim to secure blood donation resources through education and the establishment of a blood donation culture through, e.g., community-centered blood donation activities. Second, we plan to focus on blood processing and inventorying by consolidating blood manufactur-
Table 2. Transfusion-related adverse reactions confirmed by the national recipient-triggered traceback system

\begin{tabular}{|c|c|c|c|c|c|c|}
\hline Year & HIV & HCV & HBV & Malaria & Others & Total \\
\hline 1987-1996 & $10^{*}$ & 0 & 0 & 0 & - & 10 \\
\hline 1997 & 0 & 0 & 1 & 3 & - & 4 \\
\hline 1998 & 0 & 0 & 0 & 4 & - & 4 \\
\hline 1999 & 0 & 0 & 4 & 0 & - & 4 \\
\hline 2000 & 0 & 4 & 2 & 2 & - & 8 \\
\hline 2001 & 0 & 6 & 6 & 1 & - & 13 \\
\hline 2002 & 4 & 4 & 0 & 0 & - & 8 \\
\hline 2003 & 2 & 0 & 1 & 0 & - & 3 \\
\hline 2004 & 0 & 1 & 0 & 0 & - & 1 \\
\hline 2005 & 0 & 0 & 0 & 0 & - & 0 \\
\hline 2006-2013 & 0 & 3 & 1 & 3 & 6 & 13 \\
\hline 2014 & 0 & 0 & 0 & 0 & 0 & 0 \\
\hline 2015 & 0 & 0 & 0 & 0 & 2 & 2 \\
\hline 2016 & 0 & 0 & 0 & 0 & 1 & 1 \\
\hline 2017 & 0 & 0 & 0 & 0 & 3 & 3 \\
\hline 2018 & 0 & 0 & 0 & 0 & 1 & 1 \\
\hline 2019 & 0 & 0 & 0 & 0 & 1 & 1 \\
\hline 2020 & 0 & 0 & 0 & 0 & 0 & 0 \\
\hline Total & 16 & 18 & 15 & 13 & $14^{\dagger}$ & 76 \\
\hline
\end{tabular}

*HIV confirmed in patients through transfusion: 1987, one case; 1988, one case; 1989, three cases; 1991', two cases; 1992, two cases; 1993, 1 case; †transfusion-related acute lung injury (five cases), acute hemolytic transfusion reaction (four cases), sepsis (bacterial contamination in platelets, three cases), anaphylaxis (one case), suspected hepatitis A virus infection (one case). Abbreviations: HIV, human immunodeficiency virus; $\mathrm{HCV}$, hepatitis $\mathrm{C}$ virus; HBV, hepatitis B virus.

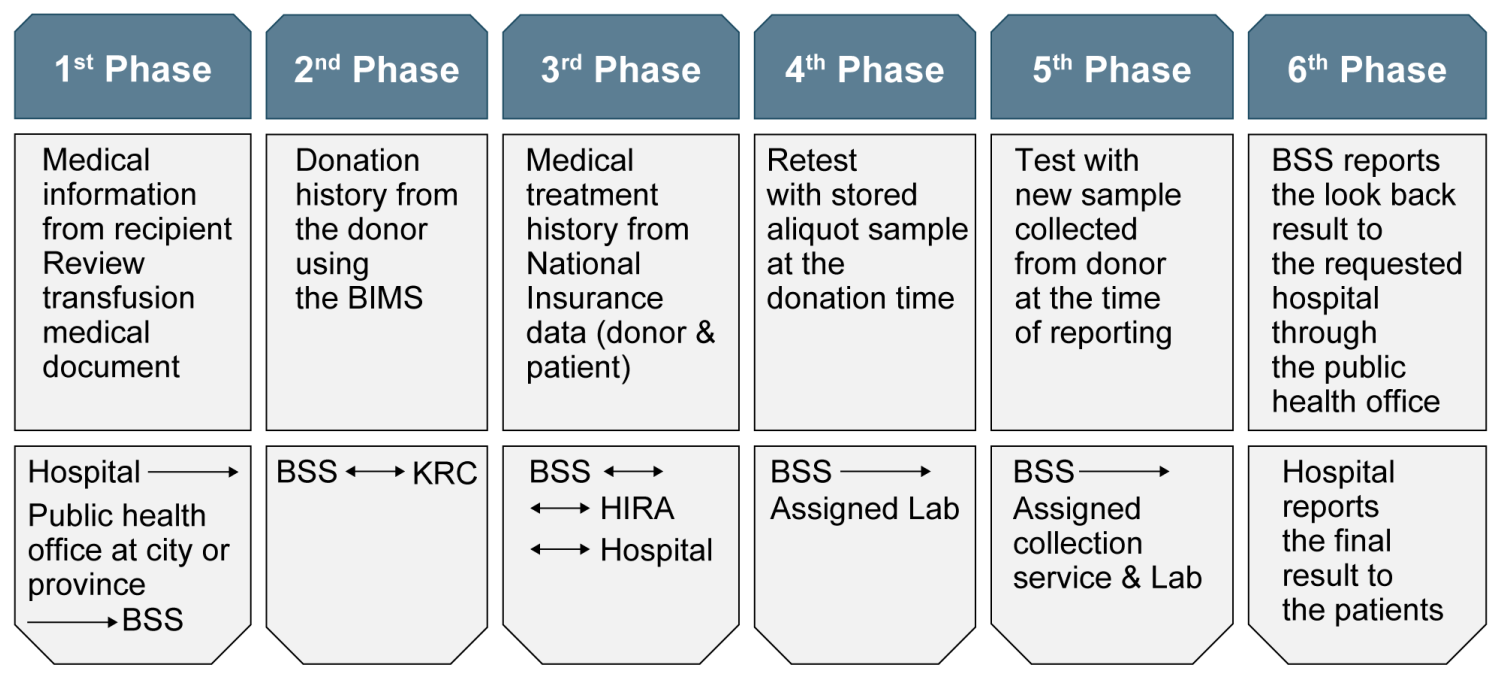

Fig. 9. Procedure for traceback processing of a suspected transfusion-related adverse reaction.

Abbreviations: BIMS: Blood Information Management System; BSS, division of Blood Safety Surveillance of the Ministry of Health and Welfare; KRC, Korean Red Cross; HIRA, Health Insurance Review \& Assessment Service. 
ing facilities and strengthening blood quality control. Third, it is necessary to support the research field of transfusion medicine for the utilization of blood resources and to pay attention to economic value creation by moving the development direction to industrialization, such as the development of test reagents and test kits.

In conclusion, blood transfusions are paramount to saving lives. However, over the last decades, there have been safety and management concerns. With careful scrutiny, governmental blood management policies are being established for the wellbeing of the people. Exciting future prospects include stem cellderived artificial blood, which may resolve the demand problem. Until then, it is our responsibility to establish the best possible policies with current resources.

\section{ACKNOWLEDGEMENTS}

The author would like to thank So-Young Kwon of the KRC for providing daily monitoring data of the red blood cell stock, and Jin Hyuk Yang and Yi Gyung Kim for cooperation with the preparation of the national traceback data.

\section{AUTHOR CONTRIBUTIONS}

Kim $\mathrm{HO}$ conducted data collection and analysis, and manuscript writing and editing the manuscript.

\section{CONFLICTS OF INTEREST}

None declared.

\section{RESEARCH FUNDING}

This study was part of a research program funded by the Division of Human Blood Safety Surveillance, Ministry of Health and Welfare (Project No. 20210409D4B-00).

\section{ORCID}

Hyun Ok Kim ～https://orcid.org/0000-0002-4964-1963

\section{REFERENCES}

1. WHO. Blood safety and availability 2020. https://www.who.int/newsroom/fact-sheets/detail/blood-safety-and-availability (Updated on Aug 2021).

2. Ali A, Auvinen MK, Rautonen J. The aging population poses a global challenge for blood services. Transfusion 2010;50:584-8.

3. Chung KW, Basavaraju SV, Mu Y, van Santen KL, Haass KA, Henry R, et al. Declining blood collection and utilization in the United States. Transfusion 2016;56:2184-92.

4. Schönborn L, Weitmann K, Greger N, Kiefel V, Hoffmann W, Greinacher A. Longitudinal changes in the blood supply and demand in North-EastGermany 2005-2015. Transfus Med Hemother 2017;44:224-31.

5. Cho HI, Seo DH, Kim HO. History of the Korean Society of Blood Transfusion and blood services in Korea. Korean J Blood Transfus 2012;23: 97-106.

6. Cho JE. National blood management system and the direction of government policy in Korea. Korean J Hematol 2010;45:81-3.

7. Kwon JR, Won EJ, Jo HJ, Choi SR, Lee K, Kim S, et al. Serious adverse transfusion reactions reported in the national recipient-triggered trace back system in Korea (2006-2014). Ann Lab Med 2016;36:335-41.

8. Kim S, Kim HO, Kim MJ, Lee SW, Shin YH, Choi YS, et al. Performance review of the National Blood Safety Improvement Project in Korea (20042009). Blood Res 2013;48:139-44.

9. Roh J, Choi SJ, Kim S, Min H, Kim HO. Blood supply and demand in Korea: What is in store for the future? Yonsei Med J 2020;61:400-5.

10. Korean Red Cross blood services head quarter. Blood services statistics 2020. https://www.bloodinfo.net/promotion_yearstats.do (Updated on Nov 2021)

11. Kim MJ, Park Q, Min HK, Kim HO. Residual risk of transfusion-transmitted infection with human immunodeficiency virus, hepatitis $C$ virus, and hepatitis B virus in Korea from 2000 through 2010. BMC Infect Dis 2012;12:160.

12. Kwon SY. Annual report of blood services in Korea, 2020. Korean J Blood Transfus 2021;32(SI):s7-17.

13. Han KS. Korean hemovigilance annual report. http://www.koheviis.or.kr (Updated on Aug 2021).

14. Choi S, Hyun J, Yu H, Cho D. ABO-incompatible transfusion events reported in written judgments and in the Korean hemovigilance system. Ann Lab Med 2021;41:493-8. 